\title{
Omaria Versus Artisunate
}

\section{Deepak Bhattacharya*}

Fight Malaria at Home, C/o Sri Radha Krishna, Kedar Gouri Road, Bhubaneswar, India

*Corresponding author: Deepak Bhattacharya, Fight Malaria at Home, C/o Sri Radha Krishna, Kedar Gouri Road, Bhubaneswar 751002, India, Tel: +91260-2640615; E-mail: oddisilab1@dataone.in

Received date: January 10, 2017; Accepted date: January 20, 2017; Published date: January 30, 2017

Copyright: $\odot 2017$ Bhattacharya D. This is an open-access article distributed under the terms of the Creative Commons Attribution License, which permits unrestricted use, distribution, and reproduction in any medium, provided the original author and source are credited.

\begin{abstract}
OMARIA is a social service in India that has lead to a unique new find to combat malariasis in core drug resistant and mutant hub. Uses tannins and ellagic acid. ACTs currently rule the drug market and are alkaloids. OMARIA uses non alkaloids. Offers a paradigm shift and fresh window. Thus there is a strong case for compare and contrast. Herein, only contrast on atomic composition basis is attempted. Interesting transpiration is got. In-depth compare is over due and is warranted.
\end{abstract}

Keywords: Drug resistant; Alkaloid; Contradictions; Ecoepidemiology; Anti-malaria

\section{Introduction}

Malaria is here to stay [1]. OMARIA - Orissa Malaria Research Indigenous Attempt 1997 [2]. It arose off the query "Why Fight Malaria ?" [3] the opportunities that this malady provides [4]. OMARIA has been in use in India to "Fight Malaria at Home Koraput" 1998-2014 [5] and the detailed making process has been reported in this journal [6]. It relates to an on foot anti-malaria effort in Koraput $\left(18^{\circ} 49 \mathrm{~N} / 82^{\circ} 43 \mathrm{E}\right)$ which is India's core-endemic-year round manifesting malaria hub. It uses the dermis of the indo medicinal fruit Dalimba (Punica Grantum (much different from the commercial Punicas).

The composition of OMARIA are non- alkaloid nor do they have any chemo property (sole, non alkaloid anti-malarial, thus far). The ACTs are known for (apparent) highest efficacy, side effects, contradictions, expensive and currently rule the related commercial roosts. It may be fruitful to compare OMARIA with artimisinin combined therapies (ACTs) which all are alkaloids and are also mild chemotherapies.

Of late much public interest has been cast towards natural compounds as source for medicaments drug discovery (medicaments). This has become intense since the award of the Nobel to the developer of the fixed dose drug from Indo-Burmese Artimissia Annua. In remote rural India a public-private enterprise has since 1998 been using the dermis of the indo Ayurvedic fruit Punica Granatum (NGO operation). It is known as OMARIA. It is giving much better results and even neutralizes hemozoin and also interdicts its production. It contains punicalagin and $\mathrm{K}+$ as an anomer. A comparison with Artisunate is attempted to bring out the distinction. OMARIA is a bottom up model and posits as full of opportunity. A conventional drug can easily be made (effective, safe, economic).

India has two types of Punica. One is commercial and the other is ayurvedic dalimbaldadima (pomegranate). The ayurvedic punica is a native member of the Indian sub-continent. It is small, harsh and has no foodljuice value. The juicy-fruit type is known as Bedana. OMARIA does not use Bedana. Anti-malarial effect of the Ayurvedic Dalimba is not indicated in the classical and or in the Govt. of India official Medicinal Herbs Compendium and or in the Sino-Nipponese texts (Table 1).

Post pluck (preferably at choloroplast stage) the fruit is cut; its aril is discarded; the rind (only) is bone dried to stone hardness in shade or in sun; hand pounded and filled @500 mg., into gelatin capsules of size No.'00'. This is OMARIA the anti-malaria capsule (Table 2).

\begin{tabular}{|c|c|c|c|c|}
\hline S.no & Drug & F Wt & $\begin{array}{l}\text { Mo Mass : } \\
\text { g/mol }\end{array}$ & Remarks \\
\hline \multicolumn{5}{|c|}{ Conventional Anti-Malarials } \\
\hline 1 & Quinine & $\mathrm{C}_{20} \mathrm{H}_{24} \mathrm{~N}_{2} \mathrm{O}_{2}$ & 324.417 & $\begin{array}{l}\mathrm{CO}_{2} \text { Venal Blood } \\
\text { Gas } \uparrow\end{array}$ \\
\hline 2 & $\begin{array}{l}\text { Choloroqui } \\
\text { ne }\end{array}$ & $\mathrm{C}_{18} \mathrm{H}_{26} \mathrm{CIN}_{3}$ & 319.872 & - do - \\
\hline 3 & Artemether & $\mathrm{C}_{16} \mathrm{H}_{26} \mathrm{O}_{5}$ & 298.374 & - do - \\
\hline 4 & Artesunate & $\mathrm{C}_{19} \mathrm{H}_{28} \mathrm{O}_{8}$ & 384.421 & - do - \\
\hline 5 & $\begin{array}{l}\text { Lumefantri } \\
\text { ne }\end{array}$ & $\mathrm{C}_{30} \mathrm{H}_{32} \mathrm{Cl}_{3} \mathrm{NO}$ & 528.939 & - do - \\
\hline 6 & Arterolane & $\mathrm{C}_{22} \mathrm{H}_{36} \mathrm{~N}_{2} \mathrm{O}_{4}$ & 392.531 & - do - \\
\hline 7 & $\begin{array}{l}\text { Piperaquin } \\
\mathrm{e}\end{array}$ & $\mathrm{C}_{29} \mathrm{H}_{32} \mathrm{Cl}_{2} \mathrm{~N}_{6}$ & 535.51 & $\begin{array}{l}\text { Dimmer : Teratogen } \\
\sim \uparrow \uparrow\end{array}$ \\
\hline \multicolumn{5}{|c|}{ OMARIA } \\
\hline 8 & Ellagic Acid & $\mathrm{C}_{14} \mathrm{H}_{6} \mathrm{O}_{8}$ & 302 & $\mathrm{CO}_{2}$ Blood Gas $\downarrow$ \\
\hline 9 & Punicalin & $\mathrm{C}_{34} \mathrm{H}_{22} \mathrm{O}_{22}$ & $780 \sim 785$ & $\downarrow \downarrow$ \\
\hline 10 & Puniclagin & $\mathrm{C}_{48}, \mathrm{H}_{28} \mathrm{O}_{30}$ & $1100 \sim 1125$ & $\downarrow \downarrow$ \\
\hline
\end{tabular}

Table 1: Chemical formula and the molecular weight of the conventional medicines. They are contrasted with the OMARIA moieties, with 'remarks'.

Synthetic Artisunate (ACTs) is considered as the most safe and effective anti-malarial as on date (most used). It is compared with one of the principal constituent moiety of OMARIA namely punicalagin. 
Page 2 of 2

Thus the twine are quite different. Figure 1 establishes the fact that the twine are 'contrasting'.

Now ellagic acid (galloyl group); ellagi-tannins and KCL are chemical entities. Hence the natural OMARIA is as good as a proto conventional drug. Such aspect, makes OMARIA a paradigm shift among the various anti-malarial options.

\begin{tabular}{|l|l|l|l|}
\hline Drug Moiety & Carbon & Hydrogen & Oxygen \\
\hline Artisunate & 19 & 28 & 8 \\
\hline Punicalagin (OMARIA) & 48 & 28 & 30 \\
\hline
\end{tabular}

Table 2: Stack distinction between OMARIA and ACTs and CQ groups of medicaments vis-à-vis mass $\backslash$ mo character and atomic compositions.

As compared to the APIs of OMARIA the ACTs have a plethora of side effects (as per author's observations). A select few are reported herein for the first time viz., down turning libido; fallopian tube problems; menstrual inconsistencies; anti-pregnancy i.e., (possible) utrine embedment failure and or unhealthy sperms (count remains good); synergistic effec $c_{t}$ with birth control pills; sleep disturbance (short REM even for field hard physical workers); long term epigastric problems; induces IBS; lower limb ectirus; hearing problems in the geriatric; etc.

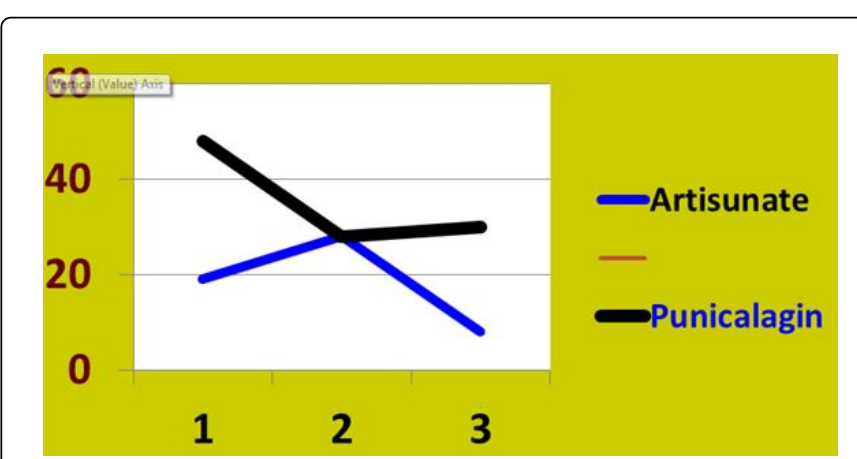

Figure 1: The distinction between OMARIA's principal moiety and the principal moiety of ACTs is presented graphically.
Along the rind powder is effective against all species of the Plasmodium. With $\mathrm{NaCl}+\mathrm{KCL}+$ Paracetamol delivers ultra rapid fever remission; myalgia WANE; and parasite clearance; also the symptoms that are well known to be associated with hemozoin. Interestingly salt(s) militates with ACT's alkalis (specially in-vivo); while they (non iodised $\mathrm{NaCl}$ ) upregulate OMARIA's and also broadens the clinical efficacy and the spectrum (Iodineliodised salt upregulates parasitemia). In OMARIA, only non iodised salts are used. As compared with ACTs this OMARIA brings to light a hitherto unique source for a (possible) novel Anti-Malaria. However, compare and contrast studies OMARIA vs. ACTs) have never been made.

\section{Acknowledgement}

To the Indian Red Cross Society (Kpt); To the missionaries Nurses; Dr. P.K. Pradhan; Mr. B M Bhuyan; The Collectors and the Additional District Magistrates; Superintends of Police; To the Emergency sections; the drivers and the helpers of Red Cross namely Mr. Naresh.

\section{References}

1. Bhattacharya D (2016) Indian Monsoon Climate and Malaria: Medical Meteorology. Journal of Malaria Control \& Elimination 5: 2-6.

2. Omaria (2008) A Novel Anti-Malaria Drug : U Tube \& Slide Show.

3. Express Pharma (2006) Fortnightly Insight for Pharma Professionals. pp: 1-15.

4. No authors Listed (2007) Why Fight Malaria? Drug One, Chandigarh, India 2: 30-36.

5. Bhattacharya D (2016) A New Natural Anti-Malaria Source India: Brief Communication. J Trop Dis 4: 187.

6. Prato M, Giribaldi G Matrix (2011) Metalloproteinase-9 and Hemozoin: Wedding Rings for Human Host and Pf Parasite in Complicated Malaria. J Trop Med 2011: 628435. 